\title{
Reducing Emissions from Diesel-Butanol-Biodiesel Engines
}

\author{
Yuan-Chung Lin*, Kassian T.T. Amesho, Syu-Ruei Jhang, Sumarlin Shangdiar, Shang-Cyuan Chen, \\ Hua-Chun Chen, Yu-Ling Liao \\ Institute of Environmental Engineering, National Sun Yat-Sen University \\ Kaohsiung 804, Taiwan
}

*Corresponding Author: yclin@faculty.nsysy.edu.tw

\begin{abstract}
This paper reports the findings on the performance and emission of a diesel generator using diesel-butanol-biodiesel was examined. The experimental results revealed that formaldehyde, acetaldehyde and acrolein account for more than $75 \%$ of aldehydes and ketones emissions. Different blends of diesel-biodiesel-butanol were used to appropriately examine the effects of fuel composition on engine-out emissions. The biodiesel used in this study was derived from waste cooking oil. The reduction is largely evident for nitro oxides, particulate matters and carbon monoxide. On the other hand, increasing the amount of biodiesel in the blends lowers engine out emissions. Amongst the fuel compositions studied, the blends with $70 \%$ diesel, $10 \%$ butanol and $20 \%$ biodiesel resulted in lowest emissions level.
\end{abstract}

Keywords: Biodiesel, Butanol, Diesel Engine, Aerosol, Aldehyde, Ketone.

\section{Introduction}

Prior studies have significantly pointed out the adverse effects of engine-out emissions on human health, greenhouse effects and environmental concerns such as toxic smog and acid rain. In order to minimize the impact of exhaust emissions, numerous researches have been conducted to improve the diesel engine such as improving the design, installing catalytic converter, and using alternative fuels from renewable-sources. Bio-fuels, such as biodiesel $\left.{ }^{[1}-5\right]$ and bio-alcohol ${ }^{[6-7]}$, seems to be the most promising solution for clean engine operations. Biodiesel is one of the most credible modern day alternatives to petroleum-based diesel as it is renewable, compatible with current economic and technological infrastructures and burnt cleanly. Biodiesel can simultaneously reduce various engine emissions: carbon monoxide (CO), hydrocarbon ( $\mathrm{HC})$, particulate matters (PM), polycyclic aromatic hydrocarbon $(\mathrm{PAH})$, polychlorinated dibenzo-p-dioxin/dibenzofuran (PCDD/F), and sulfur oxide (SO2) ${ }^{[8-11]}$. Biodiesel is commonly produced from economic plants and among others: soybeans ${ }^{[10]}$, rapeseed ${ }^{[7}$, ${ }^{12]}$, canola and sunflower ${ }^{[13]}$, to name a few. One of the major problems of using economic plants as feedstocks is the likelihood of causing food shortages and higher food costs. As for such reason, research focus has been shifted to recycled cooking oil as the feedstock of biodiesel ${ }^{[12-15]}$.

The primary objective of this study is to critically examine the effect of engine performance and exhaust emission of a diesel generator, using various dieselbiodiesel-butanol blends. This paper will contribute to the new novelty in the vehicle engines that would result in pollutant reduction, and most importantly reducing emissions from diesel engines.

\section{Methods and Materials}

\subsection{Test fuels and diesel-fueled engine generator}

Three different blends as recorded in Table 1. D100 (98\% fossil diesel and $2 \%$ biodiesel) have been used. The key fuels are produced by the Chinese Petroleum Corporation (CPC), while the biodiesel (from waste cooking oil) used in the experiment is produced by Greatec Green Energy Corporation of Taiwan. The following diesel blend fuels have been used in this study: B10W10 (10 vol\% butanol and 10 vol\% biodiesel) and B10W20 (10 vol\% butanol and 20 vol\% biodiesel), respectively.

\footnotetext{
* Corresponding author: Yuan-Chung Lin Tel.: +886 (7) 525-2000 ext. 4412; Fax: +886 (7) 525-4412

E-mail: yclin@faculty.nsysy.edu.tw
} 
Table 1. Composition of blended fuels used in the

\begin{tabular}{lccc}
\multicolumn{4}{c}{ experiment. } \\
\hline \hline \multirow{3}{*}{ Blend } & \multicolumn{2}{c}{ Composition $[\%$ Vol] } \\
& Diesel & Biodiesel & Butanol \\
\hline \hline \multirow{2}{*}{ D100 (Base Case) } & $100 \%$ & $0 \%$ & $0 \%$ \\
B10W10 & $80 \%$ & $10 \%$ & $10 \%$ \\
B10W20 & $70 \%$ & $20 \%$ & $10 \%$ \\
\hline \hline
\end{tabular}

\subsection{Sample collection}

The engine emission was monitored from tail pipe using online portable gaseous pollutant analyzer. Each sample was analyzed specifically for nitrogen oxide using a chemiluminescent detection (CLD). While carbon monoxide (CO) was detected using a nondispersive infrared detector (NDIR). Moreover, a detector flow isokinetic consoles system equipped $\left(\mathrm{PM}_{10} \& \mathrm{PM}_{2.5}\right.$ cyclone kit) with quartz fiber filters was connected on the downstream side of the diesel generator exhaust for the collection of particulate matters $\left(\mathrm{PM}_{10} \& \mathrm{PM}_{2.5}\right)$. The system could automatically tune pump flow rate by a set of pitot tube to fit the monitored flow rate of exhaust gas from engines. Then each filter sample was weighed by using an electronic analytical balance with fully automatic calibration technology to determine the net volume of collected PM.

\section{Results and Discussions}

\subsection{Engine Performance}

Brake specific fuel consumption (BSFC) and Brake thermal efficiency (BTE) are the most important parameters that measure the performance of diesel engine. Diesel fuel shows the lowest BSFC as compared to butanol-biodiesel blends in every test conducted or run. There was moderate low calorific values, high viscosity and high density in biodiesel-diesel blends which could be accounted for small increase in BSFC value ${ }^{[15]}$. Nevertheless, this challenge could be rectified with better dehydration of fuel mixtures, engines running at full load or high loads, or intake air preheated ${ }^{[12]}$. The BSFC had a reduction rate of $0.7 \%$ to $7.7 \%$ as shown in Figure 1. It was however found that the $\mathrm{BTE}$ reduction rate of the engine fell under the range of $6.3 \%$ to $9.8 \%$, as shown in Figure 2. Besides that, it was also found that the higher biodiesel content in the blends has reduced the BTE as a result of lower carbon contents in the fuel.

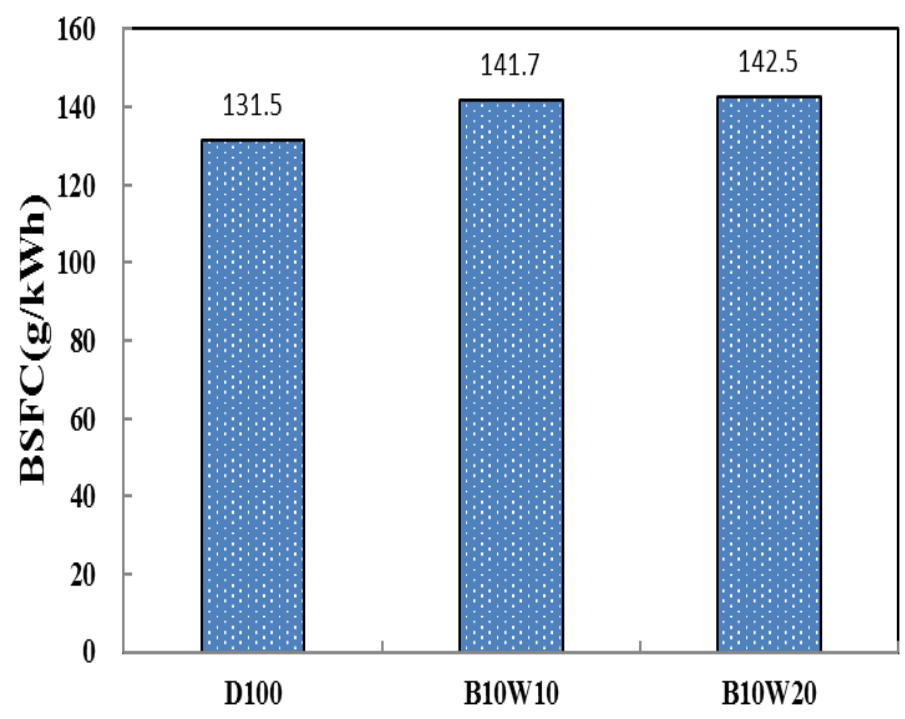

Fig 1. Brake specific fuel consumption (BSFC) for different diesel-butanol-biodiesel blends.

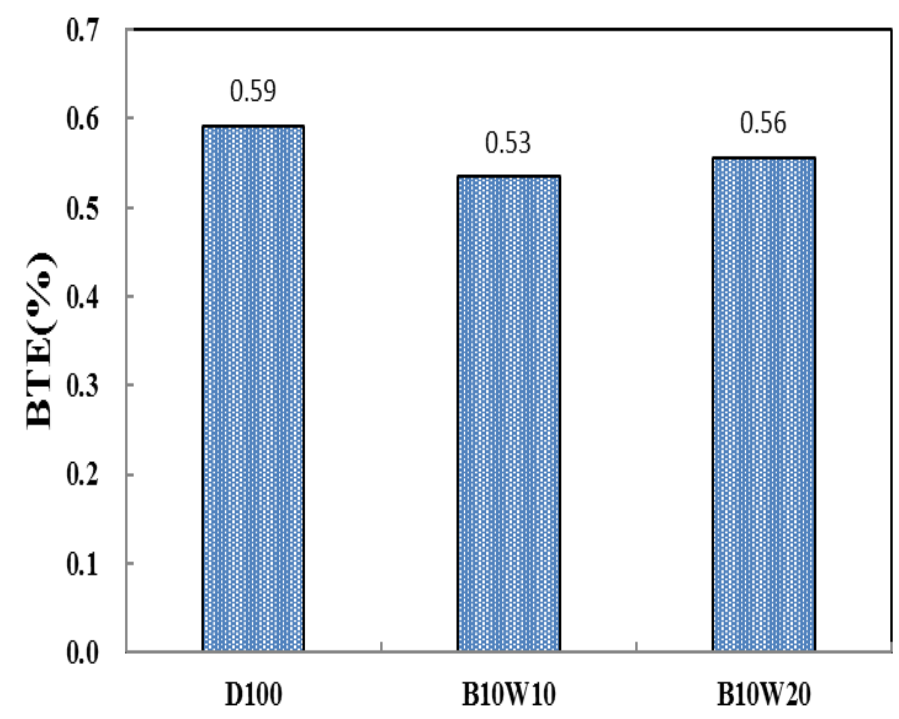

Fig 2. Brake thermal efficiency (BTE) for different dieselbutanol-biodiesel blends.

\subsection{NOx emissions}

Figure 3 shows the emissions of NOx (nitrogen oxide) under different operation conditions with the diesel-butanolbiodiesel blends. The reduction of NOx with diesel/biodiesel/butanol blends is clearly observed as decreased by $11.65 \%-13.59 \%$ compared with the petroleum diesel. 


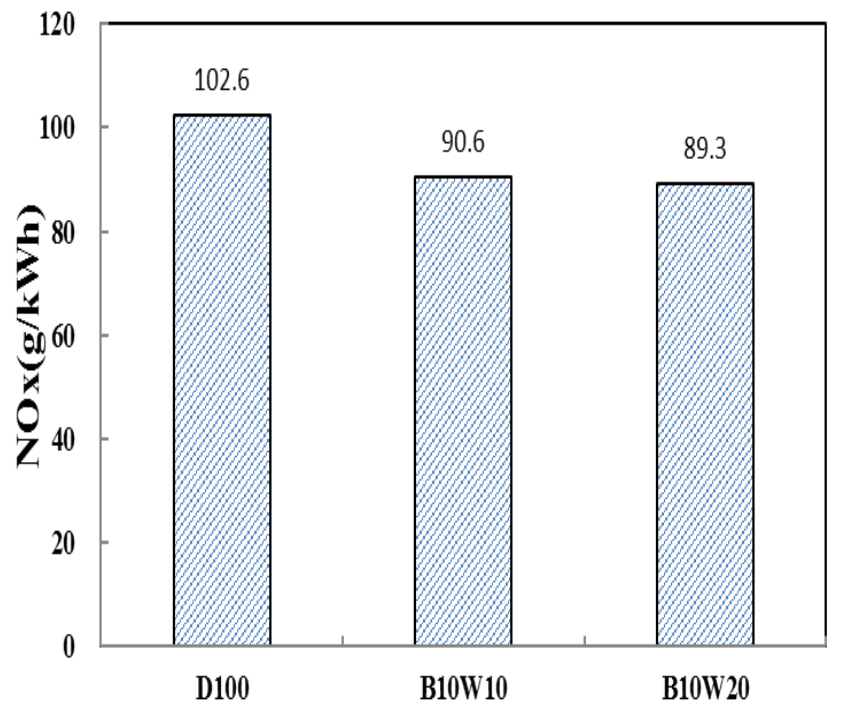

Fig 3. $\mathrm{NO}_{\mathrm{x}}$ emission for different diesel-butanol-biodiesel blends.

\subsection{Carbon Monoxide Emissions}

Figure 4 shows the measured level of carbon monoxide under different operation conditions for the diesel-butanolbiodiesel blends. Carbon monoxide is a product of incomplete combustion. This causes the minor increase of the carbon monoxide emission level as observed in Figure 4. While for the diesel-butanol-biodiesel blend, the lower diesel contents have resulted in reduced carbon monoxide emission, when compared with the emission level of neat diesel with a reduction rate of $8.5 \%$ to $10.5 \%$. Yet the emission level was slightly higher for the diesel-butanol blend, when compared against the emission level for pure diesel.

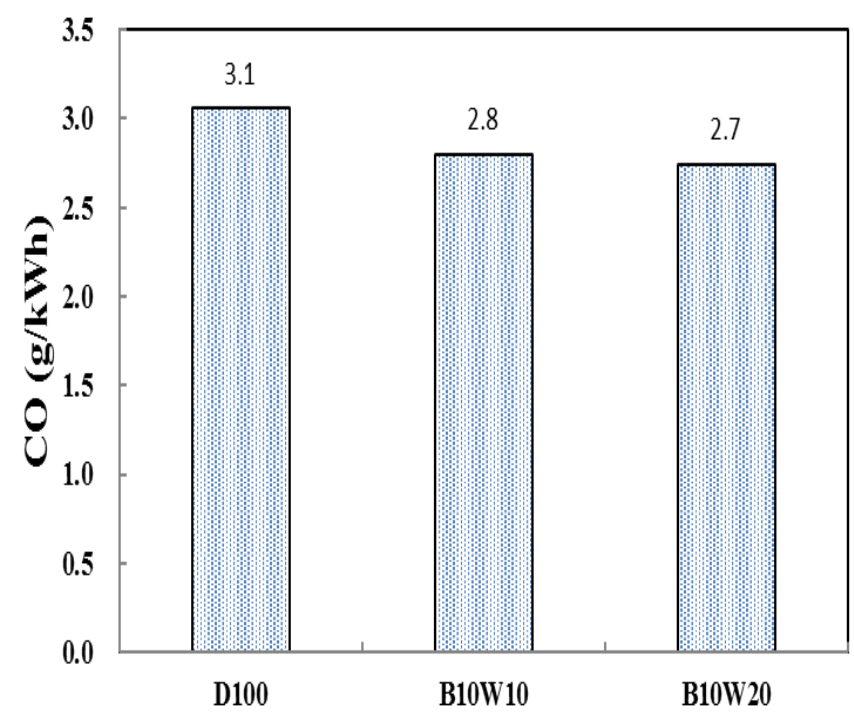

Fig 4. Emission of carbon monoxide for different dieselbutanol-biodiesel blends.

\subsection{Emission of Carbonyl (CBC) Compounds}

The composition of carbonyl compounds in the exhaust emissions for the diesel-butanol-biodiesel blends and formaldehyde, acetaldehyde and acrolein account for 75 to $90 \%$ of total carbonyl emissions, depending on fuel mixture composition. Various carbonyl (CBC) compounds were detected in the experiments, including formaldehyde, acetaldehyde, acrolein, propionaldehyde, crontonaldehyde, butyraldehyde and 2-butanone, benzaldehyde, valeradehtde and hexaldehyde. The three major CBC species in diesel emission were formaldehyde (about 62\%), acetaldehyde (about 27.5\%), butaldehyde and 2-butanone (about 3\%). The three-major species accounted for about $92 \%$ of total $\mathrm{CBC}$ compounds in the emissions.

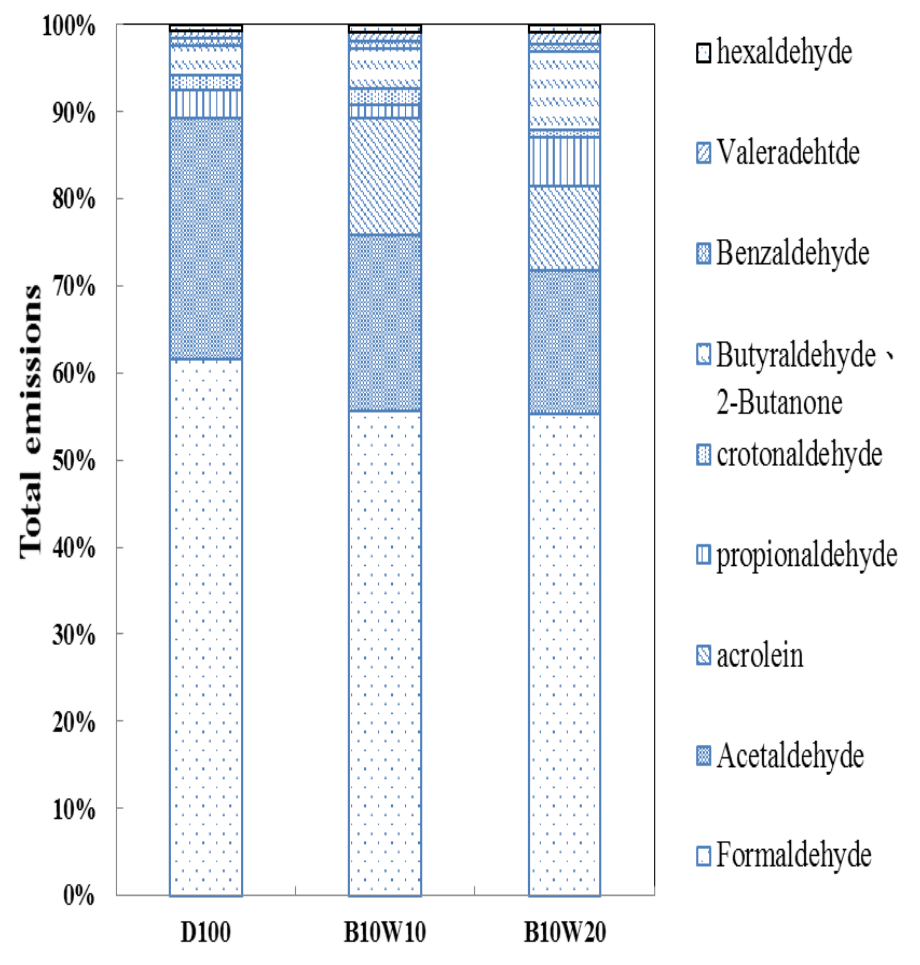

Fig 5. The composition of carbonyl emission from the diesel-butanol-biodiesel blends

\section{Formaldehyde Emissions}

The amount of formaldehyde emissions resulted from different diesel-butanol-biodiesel blends. Increasing the amount of biodiesel in the blend reduced the formaldehyde emission significantly ${ }^{[14]}$.

\section{Acetaldehyde Emissions}

The amount of acetaldehyde emissions resulted from different diesel-butanol-biodiesel blends and this has increasing the amount of biodiesel in the blend reduced the 
acetaldehyde emission significantly.

\section{Acrolein Emissions}

The amount of acrolein emissions resulted from the diesel-butanol-biodiesel blends. While increasing the amount of biodiesel, up to $30 \%$, in the blend reduced the acrolein emission.

\section{Conclusions}

The study examined the operation of a diesel generator operating with various blends of diesel-biodiesel-butanol. The biodiesel fuel used in this study was derived from waste cooking oil. Experimental results show that formaldehyde, acetaldehyde and acrolein as the major components of carbonyl compounds (CBCs) emissions. For a given amount of butanol, increasing the amount of biodiesel lowers engineout emissions. The improvement is most likely due to additional oxygen embedded in biodiesel molecule, which assists the combustion process. The results have further revealed that among the blends examined in this study, lowest emission was observed with the blend containing $40 \%$ biodiesel.

\section{Acknowledgment}

The authors would like to extend their great appreciations to the Ministry of Science and Technology (MOST) of Taiwan who made this work possible under the grant NSC102-2221-E-110-006-MY2.

\section{References}

(1) Haldar, S. K., Ghosh, B. B., \& Nag, A.: Studies on the comparison of performance and emission characteristics of a diesel engine using three degummed non-edible vegetable oils. Biomass and bioenergy, Vol. 33, No. 8, pp. 1013-1018, 2009.

(2) Kousoulidou, M., Fontaras, G., Ntziachristos, L., \& Samaras, Z.: Biodiesel blend effects on common-rail diesel combustion and emissions. Fuel, Vol. 89, No. 11, pp. 3442-3449, 2010.

(3) Qi, D., Leick, M., Liu, Y., \& Chia-fon, F. L.: Effect of EGR and injection timing on combustion and emission characteristics of split injection strategy DI-diesel engine fueled with biodiesel. Fuel, Vol. 90, No. 5, pp. 1884-1891, 2011.

(4) Debnath, B. K., Saha, U. K., \& Sahoo, N.: Theoretical Route toward the Estimation of Second Law Potential of an Emulsified Palm Biodiesel Run Diesel Engine. Journal of Energy Engineering, Vol. 140, No. 3, 13241333. 2013.

(5) Phan, A. N., \& Phan, T. M.: Biodiesel production from waste cooking oils. Fuel, Vol. 87, No. 17, pp. 3490-3496, 2008.

(6) Morais, S., Mata, T. M., Martins, A. A., Pinto, G. A., \& Costa, C. A.: Simulation and life cycle assessment of process design alternatives for biodiesel production from waste vegetable oils. Journal of Cleaner Production, Vol. 18, No. 13, pp. 1251-1259, 2010.

(7) Agathou, M. S., \& Kyritsis, D. C.: An experimental comparison of non-premixed bio-butanol flames with the corresponding flames of ethanol and methane. Fuel, Vol. 90, No. 1, pp. 255-262, 2011.

(8) Rakopoulos, D. C., Rakopoulos, C. D., Giakoumis, E. G., Dimaratos, A. M., \& Kyritsis, D. C.: Effects of butanol-diesel fuel blends on the performance and emissions of a high-speed DI diesel engine. Energy Conversion and Management, Vol. 51, No. 10, pp. 19891997, 2010.

(9) Rakopoulos, D. C., Rakopoulos, C. D., Giakoumis, E. G., Dimaratos, A. M., \& Kyritsis, D. C.: Effects of butanol-diesel fuel blends on the performance and emissions of a high-speed DI diesel engine. Energy Conversion and Management, Vol. 51, No.10, pp. 19891997, 2010.

(10) Mitsingas, C. M., \& Kyritsis, D. C.: Comparative evaluation of extinction through strain among three alcoholic butanol isomers in non-premixed counterflow flames. Journal of Energy Engineering, Vol. 140, No. 3, pp. 1335-1345, 2013.

(11) Lin, Y. C., Tsai, C. H., Yang, C. R., Wu, C. J., Wu, T. Y., \& Chang-Chien, G. P.: Effects on aerosol size distribution of polycyclic aromatic hydrocarbons from the heavy-duty diesel generator fueled with feedstock palm-biodiesel blends. Atmospheric Environment, Vol. 42, No. 27, pp. 6679-6688, 2008.

(12) Lin, Y. C., Liu, S. H., Chen, Y. M., \& Wu, T. Y.: A new alternative paraffinic-palmbiodiesel fuel for reducing polychlorinated dibenzo-p-dioxin/dibenzofuran emissions from heavy-duty diesel engines. Journal of hazardous materials, Vol. 185, No. 1, pp. 1-7, 2011.

(13) Salamanca, M., Mondragón, F., Agudelo, J. R., \& 
Santamaría, A.: Influence of palm oil biodiesel on the chemical and morphological characteristics of particulate matter emitted by a diesel engine. Atmospheric Environment, Vol. 62, pp. 220-227, 2012.

(14) Refaat, A. A.: Correlation between the chemical structure of biodiesel and its physical properties. International Journal of Environmental Science \& Technology, Vol. 6, No. 4, pp. 677-694, 2009.

(15) Lin, Y. C., Lee, W. J., Chao, H. R., Wang, S. L., Tsou, T. C., Chang-Chien, G. P., \& Tsai, P. J.: Approach for energy saving and pollution reducing by fueling diesel engines with emulsified biosolution/biodiesel/diesel blends. Environmental science \& technology, Vol. 42, No. 10, pp. 3849-3855, 2008. 